\title{
Effects of age and physical activity on response speed in knee flexor and extensor muscles
}

\author{
D. Rodríguez-Ruiz • J. M. García-Manso • \\ D. Rodríguez-Matoso $\cdot$ S. Sarmiento • \\ M. Da Silva-Grigoletto $\cdot$ R. Pisot
}

Received: 12 September 2011 / Accepted: 9 March 2013 /Published online: 3 April 2013

(C) European Group for Research into Elderly and Physical Activity (EGREPA) 2013

\begin{abstract}
This study aims to determine the normalized response speed $\left(V_{\mathrm{rn}}\right)$ in vastus lateralis $(\mathrm{VL})$ and biceps femoris (BF) muscles in different age groups using tensiomyography. Eighty-four male subjects were divided into four age groups: teenage subjects $(\mathrm{T})$; undergraduate students $(\mathrm{U})$, adult subjects (A), and the elderly group (E). Differences in $V_{\mathrm{rn}}$ were observed between $\mathrm{E}$ and $\mathrm{T}(p=0.000), \mathrm{E}$ and $\mathrm{U}(p=0.000)$, and $\mathrm{E}$ and $\mathrm{A}(p=0.018)$ for right $\mathrm{VL}$ and between $\mathrm{E}$ and $\mathrm{T}(p<0.000)$ and $\mathrm{U}(p=0.003)$ for left VL; between $\mathrm{T}$ and $\mathrm{U}(p=0.010)$ and $\mathrm{A}(p=0.000)$ for right $\mathrm{VL}$, and A $(p=0.004)$ for left VL. $V_{\mathrm{rn}}$ in the BF displayed different behavior from that of the VL, increasing moderately or stabilizing and declining slightly in $\mathrm{E}$, in right leg $(p=0.020)$. The data obtained highlighted a decline in $V_{\mathrm{rn}}$ for the VL in both legs with increasing age and, declines in $\mathrm{BF}$ response speed were observed only in $\mathrm{E}$.
\end{abstract}

Keywords Tensiomyography (TMG) $\cdot$ Muscular response speed $\cdot$ Physical activity $\cdot$ Elderly

D. Rodríguez-Ruiz and J. M. García-Manso: Collecting data and prepare statistical data. Perform the manuscript. D. Rodríguez-Matoso and S. Sarmiento: Collecting data and prepare statistical data. M. Da Silva-Grigoletto and R. Pisot: Perform the manuscript.

D. Rodríguez-Ruiz $(\bowtie) \cdot J$. M. García-Manso •

D. Rodríguez-Matoso $\cdot$ S. Sarmiento

Department of Physical Education, University of Las Palmas

de Gran Canaria, Campus Universitario de Tafira, s/n,

Edificio de Ciencias de la Actividad Física y el Deporte,

35017 Las Palmas de Gran Canaria, Spain

e-mail: drodriguez@def.ulpgc.es

M. Da Silva-Grigoletto

Andalusian Sports Medicine Centre, Seville, Spain

R. Pisot

Institute of Kinesiology Research, Science and Research Centre

of Koper, University of Primorska, Koper, Slovenia

\section{Introduction}

Loss of muscle mass is one of the leading causes of the functional limitations and disabilities associated with aging $[37,52]$ and the main cause of reduced strength in adults between 25 and 80 years of age [43]. It is particularly marked in highly sedentary (hypokinetic) subjects.

Among the various muscles most affected by disuse and inactivity, the extensors and non-postural muscles are those showing the greatest atrophy $[14,15,46]$. Atrophy involves changes in the contractile elements of muscle [35, 64, 70], a reduction in the total number of muscle fibers [29], and a loss of motor units [4, 62]. Research has shown that type II, or fast twitch, muscle fibers are more susceptible to atrophy than type I fibers [2, 19, 23, 36, 38, 53].

Of all the body systems, the neuromuscular system displays the most significant differences between sedentary, inactive, and trained or active individuals: muscles that are never used deteriorate more rapidly over time, and at an advanced age, muscle status is poorer, in sedentary subjects than in those who have maintained an adequate training regime [8, 21, 69].

Muscle strength declines more rapidly in the lower extremities than in the upper body [28, 40, 48, 68], in both sexes [9, $28]$; this poses a serious problem in elderly people with "fragility syndrome," due to the greater risk of falls [54].

Loss of muscle mass involves morphological and functional changes which impair the subjects' quality of life and give rise to problems directly affecting their ability to perform the activities of daily life [25].

The aim of this study was to analyze biomechanical characteristics of selected skeletal muscles and to determine the normalized response speed $\left(V_{\mathrm{rn}}\right)$ in knee flexor and extensor muscles in different age groups engaged in moderate physical activity using tensiomyography (TMG). 


\section{Methods}

Sample

A total of 84 male subjects were divided into four age groups (Table 1). Subject selection was based on the following criteria: teenage subjects $(\mathrm{T})$ that regularly trained, three times a week; undergraduate students (U) that were enrolled at the Faculty of Physical Education and Sport Sciences, University of Las Palmas de Gran Canaria, where they are obliged by the curriculum to engage in constant but moderate physical activity; adult subjects (A) that were active at work and engage in recreational physical activity during the week; the elderly group $(E)$ that comprised subjects aged 65 or over, whose physical activity was limited to the requirements of daily living.

The vastus lateralis (VL) and biceps femoris (BF) muscles were selected for study, as being the most involved in knee flexion and extension; this choice also enabled comparison between a postural (BF) and a non-postural muscle (VL).

All subjects, and the parents or guardians of subjects under the age of 18 , were fully informed of the procedures involved and provided written consent. The study was performed in accordance with the ethical standards laid down in the World Medical Association's Declaration of Helsinki on medical research involving human subjects.

\section{Measuring procedure}

TMG measures muscle tone [66] and contractile properties $[11-13,47]$ by means of a displacement sensor positioned directly on the skin over the muscle belly and perpendicular to it [66]; the muscle segment was selected following manufacturer's instructions [16, 22, 58]. Single maximal $1 \mathrm{~ms}$ twitch stimulation was applied in bipolar mode (100 mA), through electrodes placed at the proximal and distal ends of the muscle, avoiding the insertion tendons [31, 55, 65]; a pause was included between stimulations in order to rule out post-tetanic activation $[6,49,55]$. The reproducibility of the method and the validity of the experimental procedure used in TMG have been examined in a number of studies, which confirm its value as a high-precision technique [6, 13, 33, 50, 55, 57, 58, 63].

This measurement provides numerical information on the magnitude and timing of radial displacements of transverse

Table 1 Study age group

\begin{tabular}{lcccc}
\hline & Teenage & Undergraduate & Adult & Elderly \\
\hline Number & 21 & 21 & 21 & 21 \\
Age (years) & 14.9 & 22.8 & 56.2 & 72.4 \\
Mean (SD) & $( \pm 0.91)$ & $( \pm 1.99)$ & $( \pm 4.16)$ & $( \pm 4.93)$ \\
\hline
\end{tabular}

muscle fibers $[55,66]$. The present study focused on the normalized response speed $\left(V_{\mathrm{rn}}\right)[51,66]$.

This parameter relates the difference in radial displacement of a muscle belly between 10 and $90 \%$ of the maximal amplitude of the muscle response $\left(\Delta d_{\mathrm{r}}\right)$ and the rise time, i.e., the increase in muscle contraction time $\left(\Delta t_{\mathrm{c}}\right)$ between 10 and $90 \%$ of the muscle response (Eq.1). Valencic and Knez [66] note that in order to compare the rise time of different muscles, the rise time has to be normalized to the maximum value of a certain response. This is done by dividing the previous equation by the maximum relative displacement (Dm) of each muscle (Eq. 2). Since $\Delta d_{\mathrm{r}}$ equals $0.8 \times \mathrm{Dm}$, the normalized response speed equals 0.8 divided by the rise time (Eq. 3):

$V_{\mathrm{r}}=\frac{\Delta d_{\mathrm{r}}}{\Delta t_{\mathrm{c}}}[\mathrm{mm} / \mathrm{s}]$

$V_{\mathrm{rn}}=\frac{V_{\mathrm{r}}}{\mathrm{Dm}}=\frac{\Delta d_{\mathrm{r}} / \Delta t_{\mathrm{c}}}{\mathrm{Dm}}\left[\frac{\mathrm{mm} / \mathrm{s}}{\mathrm{mm}}\right]$

$V_{\mathrm{rn}}=\frac{0,8}{t_{\mathrm{c}}}[\mathrm{mm} / \mathrm{s}]$

\section{Statistical analysis}

Data were tested for normal distribution using the ShapiroWilk test, and independent sample means for VL and BF (both legs) were compared using the Student's $t$ test for parametric data and the Mann-Whitney adjustment for nonparametric data (significance level $p \leq 0.05$ ). Statistical analysis was performed using the SPSS-v17 software package (SPSS Inc., Chicago, IL, USA).

\section{Results}

The data obtained highlighted a decline in the response speed $\left(V_{\mathrm{rn}}\right)$ for the vastus lateralis muscle in both legs with increasing age (Figs. 1 and 2). The decline was particularly marked in elderly subjects and in the right VL (right $(32.5 \%)$ vs. left $(27.1 \%))$.

Statistically significant differences in $V_{\mathrm{rn}}$ were observed (Figs. 1 and 2) between the elderly group (E) and the other groups for the right VL ( $\mathrm{E}$ vs. T, $p=0.000$; E vs. U, $p=0.000$; and $\mathrm{E}$ vs. A, $p=0.018$ ) and between the elderly group and the teenage and undergraduate groups for the left VL (E vs. T, $p<0.000$; E vs. U, $p=0.003$ ). Significant differences were also found between the teenage group and the undergraduate and adult groups for the right $\mathrm{VL}$ ( T vs. U, $p=0.010$; T vs. A, $p=0.000$ ), and with respect to the adult group for the left $\mathrm{VL}$ ( $\mathrm{T}$ vs. $\mathrm{A}, p=0.004)$. 


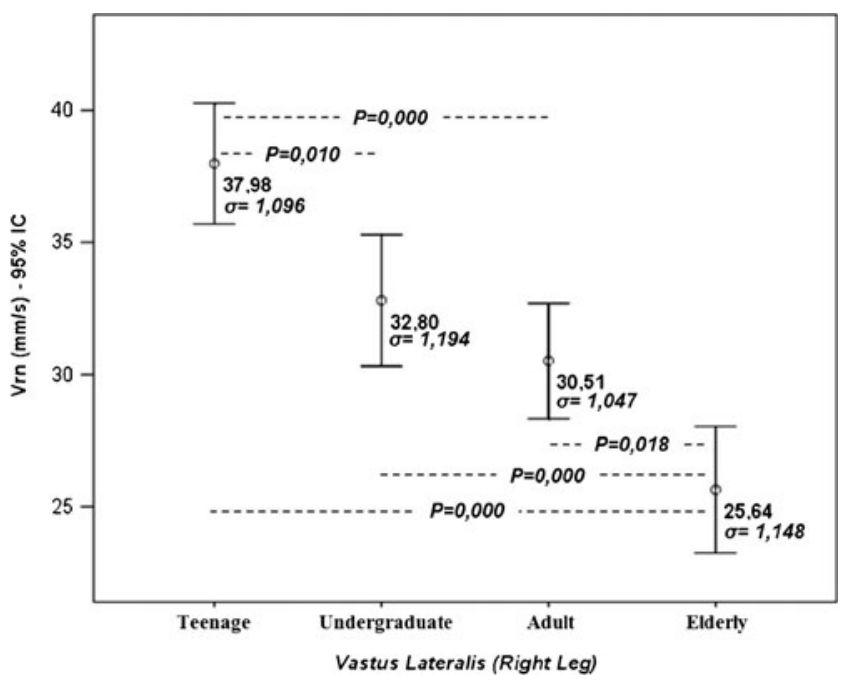

Fig. 1 Mean values for normalized response speed $\left(V_{\mathrm{rn}}\right)$ expressed in millimeter per second, at a $95 \%$ confidence interval $(95 \% \mathrm{CI})$ and $\sigma$ (standard error of mean), for the right vastus lateralis muscle (VL) for each of the study groups $(p \leq 0.05)$

Muscle contraction speed in the BF (Fig. 3) displayed different behavior from that of the VL (Fig. 4), increasing moderately or stabilizing until the fifth or sixth decade of life, and thereafter declining slightly in the elderly group. The decline in speed was more marked in the right leg $(p=0.020)$.

\section{Discussion}

The results indicated a decline in $V_{\mathrm{rn}}$ in the VL (both legs) with increasing age. By contrast, values in the BF tended to remain stable throughout life, with only a slight decline in

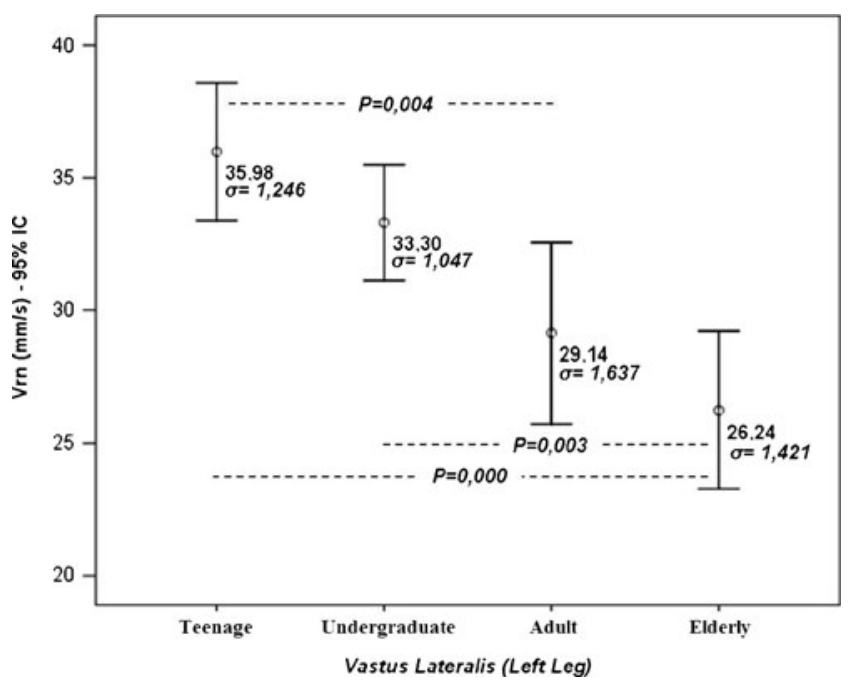

Fig. 2 Mean values for normalized response speed $\left(V_{\mathrm{rn}}\right)$ expressed in millimeter per second, at a $95 \%$ confidence interval $(95 \% \mathrm{CI})$ and $\sigma$ (standard error of mean), for the left vastus lateralis muscle (VL) for each of the study groups $(p \leq 0.05)$

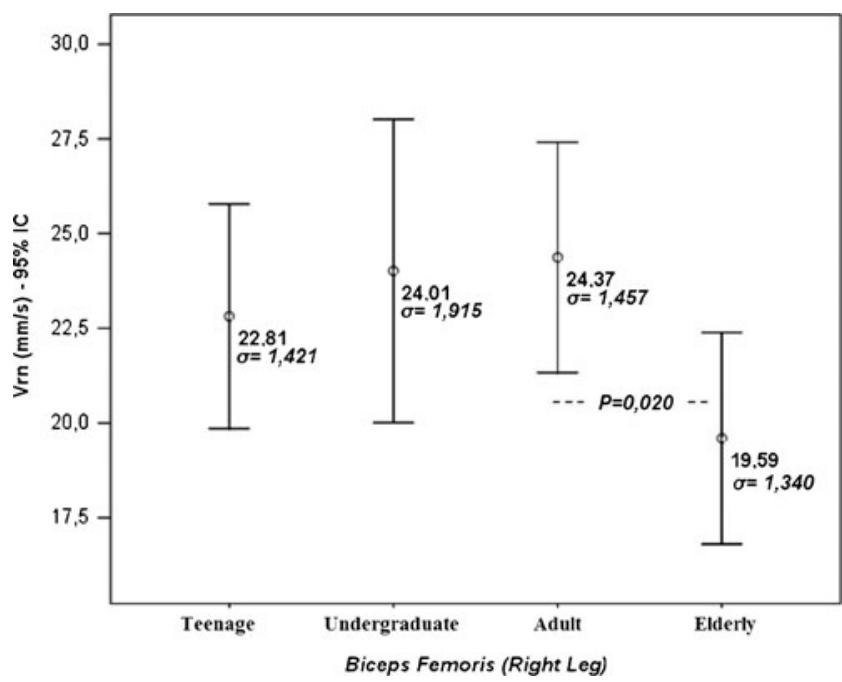

Fig. 3 Mean values for normalized response speed $\left(V_{\mathrm{rn}}\right)$ expressed in millimeter per second, at a $95 \%$ confidence interval $(95 \% \mathrm{CI})$ and $\sigma$ (standard error of mean), for the right biceps femoris muscle (BF) for each of the study groups $(p \leq 0.05)$

the elderly group (E). These functional changes in muscle response in elderly subjects reduce their functional capacity and their ability to perform the tasks of daily life, impairing postural balance control $[20,27]$ and thus increasing the risk of falls $[7,42,54,61]$. Additionally, the main muscles used in walking (knee extensors and plantar flexors) lose their functional capacity more rapidly than the muscles used in maintaining postural balance $[5,39,40,45,48,68]$.

The decline in response speed $\left(V_{\mathrm{rn}}\right)$ observed here may be considered indicative of the changes in muscle response taking place due to aging. The magnitude of the decline reflects the loss of muscle mass, a decrease in contractile

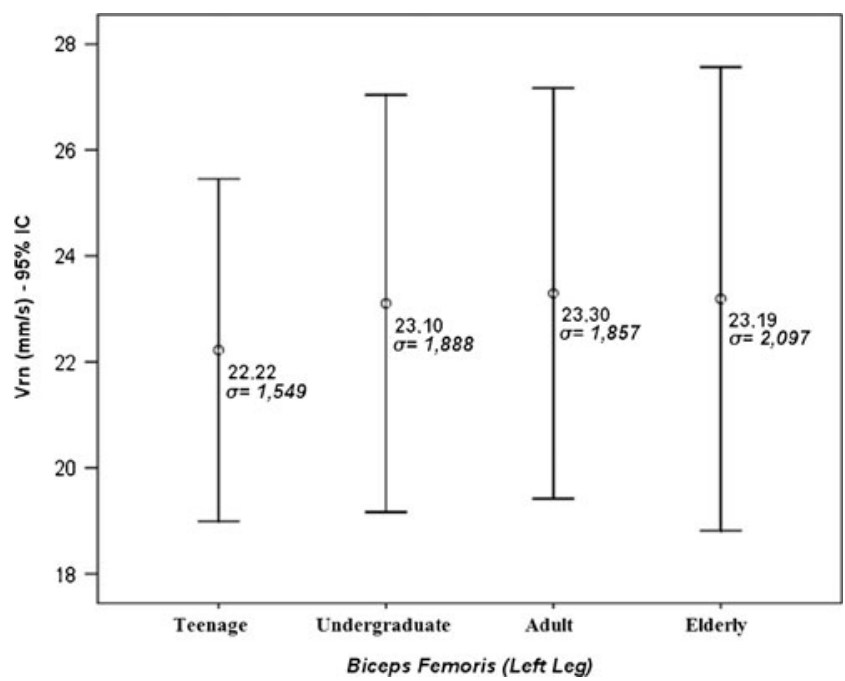

Fig. 4 Mean values for normalized response speed $\left(V_{\mathrm{rn}}\right)$ expressed in millimeter per second, at a $95 \%$ confidence interval $(95 \% \mathrm{CI})$ and $\sigma$ (standard error of mean), for the left biceps femoris muscle (BF) for each of the study groups $(p \leq 0.05)$ 
elements $[1,35,64,70]$, neuromuscular alterations $[4,43$, 62], and changes in functional balance [17].

Pisot et al. [46] note some dissociation between the contractile changes after long term of complete inactivity occurring at whole-muscle level and those observed at single-fiber level, and their associated changes in myosin heavy chain (MHC) composition. It has been clearly shown that type II muscle fibers are more susceptible to atrophy than type I fibers $[2,3,30,32,59]$, although a number of studies report similar changes in the two types of fiber [56]. Furthermore, other authors found correlation between high values in the muscle contraction time (Tc) with the highest percentage of type I fibers $[30,31]$ or with the increased presence of myosin heavy chain (MHC-I) [18].

The extent of changes in muscle composition and response potential is directly linked to the subject's level of physical activity, as long as functional capacity is not governed by some other pathology. Aagard et al. [1] note that strength training induces adaptation of skeletal muscle plasticity as well as improved muscle response in elderly subjects even at a very old age. In the present study, the level of physical activity declined with age, being greatest in the teenage group and lowest in the elderly group. Response speed in the vastus lateralis muscle diminished at a similar rate to physical activity; similar findings have been reported by other authors $[8,21,69]$.

The results indicated that the biceps femoris (Fig. 2) had a lower response speed and behaved differently to the VL with increasing age: over the first five or six decades of life, muscle response speed appeared to undergo no significant changes. However, a moderate but statistically significant decline was noted between the adult and elderly groups $(p=0.020)$ for the right BF, indicating a serious impairment of physical activity in the oldest subjects.

Analysis of the results obtained here should take into account that changes in muscle response may be due not only to age but also to the amount and type of physical activity in each group.

The findings of the present study with regard to age-related changes in muscle response speed match those reported by Clark et al. [10] in a study of elderly subjects with limited mobility, elderly subjects with no limitations and middle-aged subjects. These authors found the greatest decline in response speed in elderly subjects with limited mobility and the smallest decline in middle-aged subjects. The decline was more marked in knee extensor muscles (VL, VM, and RF) than in knee flexor muscles (BF and ST). Asaka and Wang [5] report that, with advancing age, the center of pressure moves forward, prompting a constant need for posture rebalancing using the knee flexor muscles, which thus compensate for the progressive loss of knee extensor strength.

It is generally recognized that the ability to make fast movements (dynamic strength) declines more rapidly with age than the ability to maintain static balance (static strength) [26, 27, 34, 60, 67]. It also seems clear that diminished displacement speed increases the risk of falls in elderly subjects $[24,41,44]$.

\section{Conclusions}

The results obtained indicated a decline in the normalized response speed $\left(V_{\mathrm{rn}}\right)$ of the vastus lateralis muscle in both legs as subjects grow older and engage in less physical activity. The decline was especially apparent in the elderly group compared to the teenage and undergraduate groups, and between the adult and teenage groups.

In the teenage, undergraduate, and adult groups, flexor muscles behaved differently from extensors. While VL response speed decreased with age, BF increased slightly or remained stable over the first five decades of life; declines in $\mathrm{BF}$ response speed were observed only in the elderly group.

The results confirmed that TMG monitoring of muscle response speed using the VL provides an efficient indicator of loss of quality in dynamic movements involving lower limb muscles (ankle and knee joints).

Acknowledgments The authors are grateful to all the subjects who took part in the study and to the families of the young and elderly participants.

\section{Disclosures}

Conflict of interest D. Rodríguez-Ruiz, J. M. García-Manso, D. Rodríguez-Matoso, S. Sarmiento, M. Da Silva-Grigoletto, R. Pisot declare that they have no conflict of interest.

Informed consent All subjects, and the parents or guardians of subjects under the age of 18 , were fully informed of the procedures involved and provided written consent.

Human \& animal studies This article does not contain any studies with human or animal subjects performed by the any of the authors.

Ethical statement The study was performed in accordance with the ethical standards laid down in the World Medical Association's Declaration of Helsinki on medical research involving human subjects.

\section{References}

1. Aagard P, Suetta C, Caserotti P, Magnusso SP, Kjaer M (2010) Role of the nervous system in sarcopenia and muscle atrophy with aging: strength training as a countermeasure. Scand J Med Sci Sports 20(1):46-64

2. Akima H, Kawakami Y, Kubo K, Sekiguchi C, Ohshima H, Miyamoto A, Fukunaga T (2000) Effect of short-duration spaceflight on thigh and leg muscle volume. Med Sci Sports Exerc 32:1743-1747 
3. Andersen L, Andersen J, Magnuson P, Suetta C, Madsen J, Christensen L, Aagaard P (2005) Changes in the human muscle force-velocity relationship in response to resistance training and subsequent detraining. J Appl Physiol 99:87-94

4. Antonutto G, Capelli C, Girardis M, Zamparo P, di Prampero PE (1999) Effects of microgravity on maximal power of lower limbs during very short efforts in humans. J Appl Physiol 86:85-92

5. Asaka T, Wang Y (2008) Effects of aging on feedforward postural synergies. J Hum Kinet 20:63-70

6. Belic A, Knez N, Karba R, Valencic V (2000) Validation of the human muscle model. Proceedings of the 2000 Summer Computer Simulation Conference, 16-20. July 2000, Vancouver, British Columbia. Session 1: Issues on Whole Body Modeling

7. Brouwer BK, Musselman BK, Culham E (2004) Physical function and health status among seniors with and without a fear of falling. Gerontology 50(3):135-141

8. Buckwalter JA (1997) Decrease mobility in elderly: the exercise antidote. Phys Sports Med 25(9):126-133. doi:10.3810/ psm.1997.09.1516

9. Camiña Fernández F, Cancela Carral JM, Romo Pérez V (2001) La prescripción del ejercicio físico para personas mayores. Valores normativos de la condición física. Revista Internacional de Medicina y Ciencias de la Actividad Física y el Deporte 1(2):136154

10. Clark DJ, Patten C, Reid KF, Carabello RJ, Phillips EM, Fielding RA (2010) Impaired voluntary neuromuscular activation limits muscle power in mobility-limited older adults. J Gerontol A Biol Sci Med Sci 65A(5):495-502

11. Dahmane RG, Djordjevic S, Šimunic B, Valencic V (2005) Spatial fiber type distribution in normal human muscle histochemical and tensiomyographical evaluation. J Biomech 38(12):24512459

12. Dahmane R, Djordjevic S, Smerdu V (2006) Adaptive potential of human biceps femoris muscle demonstrated by histochemical, immunohistochemical and mechanomyographical methods. Med Bio Eng Comput 44(11):999-1006

13. Dahmane R, Knez N, Valencic V, Erzen I (2000) Tensiomyography, a non-invasive method reflecting the percentage of slow muscle fiber in human skeletal muscles. Book of Abstract: Life Sciences 2000, Gozd Martuljek, Slovenia, September 28 to October 1, 2000, pp./str. 29

14. De Boer MD, Seynnes OR, Di Prampero PE, Pisot R, Mekjavic IB, Biolo G, Narici MV (2008) Effect of 5 weeks horizontal bed rest on human muscle thickness and architecture of weight bearing and non-weight bearing muscle. Eur J Appl Physiol 104(2):401-407

15. Di Prampero PE, Narici MV (2003) Muscles in microgravity: from fibres to human motion. J Biomech 36:403-412

16. Djordjevic S, Valencic V, Knez N, Dahmane R, Jurcic-Zlobec B, Bednarik J, Simunic B, Kersevan K, Godina N (2000) Contractile properties of skeletal muscles of two groups of sportsmen-sprinters and cyclist measured by Tensiomyography. 2000 Pre-Olympic Congress, Brisbane, Australia, Abstract 220

17. Enoka RM, Christou EA, Hunter S, Kornatz K, Semmler J, Taylor A, Tracy B (2003) Mechanisms that contribute to differences in motor performance between young and old adults. J Electromyogr Kinesiol 13(1):1-12

18. Essen-Gustavsson B, Borges O (1986) Histochemical and metabolic characteristics of human skeletal muscle in relation to age. Acta Physiol Scand 126:107-114

19. Fitts RH, Riley DR, Widrick JJ (2000) Microgravity and skeletal muscle. J Appl Physiol 89:823-839

20. Foldvari M, Clark M, Laviolette L, Bernstein MJA, Castanda C, $\mathrm{Pu}$ CT, Hausdorff JM, Fielding RA, Fiatarone-Singh MA (2000) Association of muscle power with functional status in community-dwelling elderly women. J Gerontol: Biol Med Sci 55A: M192-M199
21. González JM, Valero M (2000) Indicaciones y sugerencias sobre el entrenamiento de fuerza y resistencia en ancianos. Int J Med Sci Physic Act Sport 1:41-48

22. Gorelick ML, Brown JM (2007) Mechanomyographic assessment of contractile properties within seven segments of the human deltoid muscle. Eur J Appl Physiol 100(1):35-44

23. Grimby G, Danneskiold-Samsoe B, Hvid K, Saltin B (1982) Morphology and enzyme capacity in arm and leg muscles in 78-81 year old men and women. Acta Physiol Scand 115:125-134

24. Holbein J, Mary JA, McDermott K, Shaw C, Demchak J (2007) Validity of functional stability limits as a measure of balance in adults aged 23-73 years. Ergonomics 50(5):631-646

25. Hunter GR, McCarthy JP, Bamman MM (2004) Effects of resistance training on older adults. Sports Med 34(5):329-348

26. Hwang IS, Huang CT, Cherng CC (2006) Postural fluctuations during pointing from a unilateral or bilateral stance. Hum Mov Sci 25:275-291

27. Izquierdo M, Ibanez J, Gorostiaga E, Garrues M, Zuñiga A, Antón A, Larrión JL, Hakkinen K (1999) Maximal strength and power characteristics in isometric and dynamic actions of the upper and lower extremities in middle-aged and older men. Acta Physiol Scand 167:57-68

28. Janssen I, Heymfield SB, Wang Z, Ross R (2000) Skeletal muscle mass and distribution in 468 men and women aged $18-88$ yr. J Appl Physiol 89:81-88

29. Kamel H (2003) Sarcopenia and aging. Nutr Rev 61(5):157-167

30. Klitgaard H, Mantoni M, Schiaffino S, Ausoni S, Gorza L, Laurent-Winter C, Schnohr P, Saltin B (1990) Function, morphology and protein expression of ageing skeletal muscle: a crosssectional study of elderly men with different training backgrounds. Acta Physiologica Scandinavica 140:41-54

31. Knez N, Valencic V (2000) Proceedings of the ninth Electrochemical and Computer Science Conference ERK 2000, 21-23, September 2000, Portoroz, Slovenia. Ljubljana: IEEE Region 8, Slovenian section IEEE, Vol. B, pp 301-304

32. Kosek D, Kim J, Petrella J, Cross J, Bamman M (2006) Efficacy of 3 days/wk resistance training on myofiber hypertrophy and myogenic mechanisms in young vs. older adults. J Appl Physiol 101:531-544

33. Krizaj D, Simunic B, Zagar T (2008) Short-term repeatability of parameters extracted from radial displacement of muscle belly. $\mathrm{J}$ Electromyogr Kinesiol 18:645-651

34. Lanza IR, Towse TF, Caldwell GE, Wigmore DM, Kent-Braun JA (2003) Effects of age on human muscle torque, velocity, and power in two muscle groups. J Appl Physiol 95:2361-2369

35. Larsson L, Li X, Berg HE, Frontera WR (1996) Effects of removal of weight-bearing function on contractility and myosin isoform composition in single human skeletal muscle cells. Pflügers Archiv Eur J Physiol 432:320-328

36. LeBlanc A, Rowe R, Schneider V, Evans H, Hedrick T (1995) Regional muscle loss after short duration spaceflight. Aviat Space Environ Med 66:1151-1154

37. Leenders N (2003) The elderly. In: Ehrman JK, Gordon PM, Visich PS, Keteyian SJ (eds) Clinical exercise physiology. Human Kinetics, Champaing

38. Lidboe CF, Torvik A (1982) The effects of ageing, cachexia and neoplasms on striated muscle. Quantitative histological and histochemical observations on an autopsy material. Acta Neuropathol 57:85-92

39. Loram ID, Maganaris CN, Lakie M (2004) Paradoxical muscle movement in human standing. J Physiol 556:683-689

40. Macaluso A, de Vito G (2004) Muscle strength, power and adaptations to resistance training in older people. Eur J Appl Physiol 91:450-472

41. Maciaszek J (2010) Muscle strength and aerobic endurance as factors differentiating falling and non-falling men over 70 years. J Hum Kinet 25:35-40 
42. Maki BE, Holliday PJ, Topper AK (1994) A prospective study of postural balance and risk of falling in an ambulatory and independent elderly population. J Gerontol 49:M72-M84

43. McArdle WD, Katch FI, Katch FL (2001) Exercise physiology: energy, nutrition, and human performance, 5th edn. Lippincott Williams \& Wilkins, Hagerstown

44. Melzer I, Benjuya N, Kaplanski J (2004) Postural stability in the elderly: a comparison between fallers and non-fallers. Age Ageing 33(6):602-607

45. Onambele GL, Narici MV, Maganaris CN (2006) Calf muscletendon properties and postural balance in old age. J Appl Physiol 100:2048-2056

46. Pisot R, Narici MV, Simunic B, De Boer M, Seynnes O, Jurdana M, Biolo G, Mekjavic IB (2008) Whole muscle contractile parameters and thickness loss during 35-day bed rest. Eur J Appl Physiol 104(2):409-414

47. Pisot R, Valencic V, Simunic B (2002) Influence of biomechanical properties of particular skeletal muscles on child motor development. Ann Ser Hist Nat 12:99-106

48. Reeves ND, Narici MV, Maganaris CN (2006) Musculoskeletal adaptations to resistance training in old age. Man Ther 11:192-196

49. Rodríguez-Matoso D, Rodríguez-Ruiz D, Quiroga ME, Sarmiento S, De Saa Y, García-Manso JM (2010) Tensiomiografía, utilidad y metodología en la evaluación muscular. Revista Internacional de Medicina y Ciencias de la Actividad Física y el Deporte 10(40): $620-629$

50. Rodríguez-Matoso D, Rodríguez-Ruiz D, Sarmiento S, Vaamonde D, Da Silva-Grigoletto ME, García-Manso JM (2010) Reproducibility of muscle response measurements using tensiomyography in a range of positions. Rev Andal Med Deporte 3(3):81-86

51. Rodríguez-Ruiz D, Rodríguez-Matoso D, Quiroga ME, Sarmiento S, Da Silva-Grigoletto ME, García-Manso JM (2012) Study of extensor and flexor musculature in the knees of male and female volleyball players. Eur J Sport Sci 112(5):399-407

52. Rouvenoff R (2001) Origins and clinical relevance of sarcopenia. Can J Appl Physiol 26(1):78-89

53. Scelsi R, Marchetti C, Poggi P (1980) Histochemical and ultrastructural aspects of $\mathrm{m}$. vastus lateralis in sedentary old people (65-89 years). Acta Neuropathol 51:99-105

54. Schrager M, Bandinelli S, Maggi S, Ferrucci L (2003) Sarcopenia: twenty open questions for research agenda. Basic Appl Myol 13(4):203-208

55. Simunic B (2003) Model of longitudinal contractions and transverse deformations in skeletal muscles. Doctoral Thesis. Ljubljana

56. Simunic B, Degens H, Rittweger J, Narici M, Mekjavi IB, Pisot R (2011) Noninvasive Estimation of Myosin Heavy Chain Composition in Human Skeletal Muscle. Med Sci Sports Exerc 43(9):16191625
57. Simunic B, Krizaj D, Narici M, Pisot R (2010) Twitch parameters in transversal and longitudinal biceps brachii response. Annales Kinesiologiae 1:61-80

58. Simunic B, Valencic V (2001) Proceedings of X Electrochemical and Computer Science Conference. IEEE Region 8, Slovenian Section IEEE, Vol. B, pp 363-366. September 24-26, 2001. Portoroz (Eslovenia)

59. Singh MAF, Ding W, Manfredi T, Solares G, O’Neill E, Clements K, Ryan N, Kehayias J, Fielding R, Evans W (1999) Insulin-like growth factor I in skeletal muscle after weight-lifting exercise in frail elders. Am J Physiol Endocrinol Metab 277:E137-E143

60. Skelton DA, Greig CA, Davies JM, Young A (1994) Strength, power and related functional ability of healthy people aged 6589 years. Age Ageing 23:371-377

61. Stalenhoef PA, Diederiks JP, Knottnerus JA, Kester AD, Crebolder HF (2002) A risk model for the prediction of recurrent falls in community-dwelling elderly: a prospective cohort study. J Clin Epidemiol 55(11):1088-1094

62. Stolberg E, Fawcett P (1982) Macro EMG in healthy subjects of different ages. J Neurol Neurosurg Psychiatry 5:870-878

63. Tous-Fajardo J, Moras G, Rodríguez-Jiménez S, Usach R, Doutres DM, Maffiuletti NA (2010) Inter-rater reliability of muscle contractile property measurements using non-invasive tensiomyography. J Electromyogr Kinesiol 20(4):761-766

64. Trappe S, Trappe T, Gallagher P, Harber M, Alkner B, Tesch P (2004) Human single muscle fibre function with 84 day bed-rest and resistance exercise. J Physiol 557:501-513

65. Valencic V (2002) Method for selective and non-invasive detection of skeletal muscles contraction process. International Application Published under the Patent Cooperation Treaty (PCT). No. WO 02/ 074167 A1

66. Valencic V, Knez N (1997) Measuring of the skeletal muscles' dynamic properties. Artific Org 21:240-242

67. Valour D, Ochala J, Ballay Y, Pousson M (2003) The influence of ageing on the force-velocity-power characteristics of human elbow flexor muscles. Exp Gerontol 38:387-395

68. Vandervoort AA (2002) Aging of the human neuromuscular system. Muscle Nerve 25:17-25

69. Wilmore JH, Costill DL (2004) Physiology of sport and exercise, 3rd edn. Human Kinetics, Champaign

70. Young A, Stokes M, Crowe M (1984) Size and strength of the quadriceps muscle of old and young women. Eur J Clin Invest $14: 282-287$

We can declare that is original research. 